\title{
Relationships between serum MCP-1 and subclinical kidney disease: African American- Diabetes Heart Study
}

\author{
Mariana Murea ${ }^{1 *+}$, Thomas C Register ${ }^{2 \dagger}$, Jasmin Divers ${ }^{3}$, Donald W Bowden ${ }^{4}$, J Jeffrey Carr ${ }^{5}$, Caresse R Hightower ${ }^{5}$, \\ Jianzhao Xu ${ }^{4}, \mathrm{~S}$ Carrie Smith ${ }^{4}$, Keith A Hruska ${ }^{6}$, Carl D Langefeld ${ }^{3}$ and Barry I Freedman ${ }^{*^{*}}$
}

\begin{abstract}
Background: Monocyte chemoattractant protein-1 (MCP-1) plays important roles in kidney disease susceptibility and atherogenesis in experimental models. Relationships between serum MCP-1 concentration and early nephropathy and subclinical cardiovascular disease (CVD) were assessed in African Americans (AAs) with type 2 diabetes (T2D).

Methods: Serum MCP-1 concentration, urine albumin:creatinine ratio (ACR), estimated glomerular filtration rate (eGFR), and atherosclerotic calcified plaque (CP) in the coronary and carotid arteries and infrarenal aorta were measured in 479 unrelated AAs with T2D. Generalized linear models were fitted to test for associations between MCP-1 and urine ACR, eGFR, and CP.

Results: Participants were 57\% female, with mean \pm SD (median) age 55.6 \pm 9.5 (55.0) years, diabetes duration 10.3 \pm 8.2 (8.0) years, urine ACR 149.7 \pm 566.7 (14.0) $\mathrm{mg} / \mathrm{g}$, CKD-EPI eGFR 92.4 $\pm 23.3(92.0) \mathrm{ml} / \mathrm{min} / 1.73 \mathrm{~m}^{2}, \mathrm{MCP}-1$ $262.9 \pm 239.1(224.4) \mathrm{pg} / \mathrm{ml}$, coronary artery CP $280.1 \pm 633.8$ (13.5), carotid artery CP $47.1 \pm 132.9$ (0), and aorta CP 1616.0 2864.0 (319.0). Adjusting for age, sex, smoking, $\mathrm{HbA}_{1 c}$, BMI, and LDL, serum MCP-1 was positively associated with albuminuria (parameter estimate $0.0021, P=0.04$ ) and negatively associated with eGFR (parameter estimate $-0.0003, P=0.001)$. MCP-1 remained associated with eGFR after adjustment for urine ACR. MCP-1 levels did not correlate with the extent of $\mathrm{CP}$ in any vascular bed, $\mathrm{HbA}_{1 c}$ or diabetes duration, but were positively associated with BMI. No interaction between BMI and MCP-1 was detected on nephropathy outcomes.
\end{abstract}

Conclusions: Serum MCP-1 levels are associated with eGFR and albuminuria in AAs with T2D. MCP-1 was not associated with subclinical CVD in this population. Inflammation appears to play important roles in development and/or progression of kidney disease in AAs.

Keywords: African Americans, Albuminuria, Atherosclerotic calcified plaque, Diabetes, GFR, MCP-1

\section{Background}

Inflammation, influx of circulating inflammatory cells, synthesis and secretion of chemokines and cytokines play important roles in diabetic kidney disease and atherosclerosis [1,2]. The relationship between serum chemokine monocyte chemoattractant protein-1 (MCP-1, or CCL2) levels with kidney disease and subclinical cardiovascular disease (CVD) has not been evaluated in the

\footnotetext{
*Correspondence: mmurea@wakehealth.edu; bfreedma@wakehealth.edu ${ }^{\dagger}$ Equal contributors

'Department of Internal Medicine/Nephrology, Wake Forest School of Medicine, Medical Center Boulevard, Winston-Salem, NC 27157-1053, USA Full list of author information is available at the end of the article
}

African American (AA) population. Macrophages contribute to the pathophysiology of atherosclerosis, albuminuria, diabetic nephropathy (DN), and kidney failure $[3,4]$. Macrophage trafficking and influx to the blood vessel wall is driven in part by chemokines, and MCP-1 inhibition delays formation of atherosclerotic plaque [5]. In experimental and human DN, macrophages are the principal infiltrating leukocyte population and the degree of macrophage influx and MCP-1 expression in the glomerular and interstitial compartments correlate with albuminuria and kidney function outcome [4,6-8]. Experimentally, MCP-1 suppression ameliorated albuminuria and kidney interstitial disease [7].

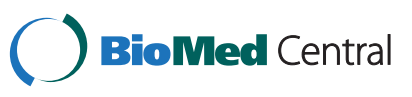


Albuminuria and kidney disease are strongly linked with CVD. Presence of a graded association has been demonstrated between estimated glomerular filtration rate (eGFR) and albuminuria, with cardiovascular events, mortality, and presence and severity of coronary artery calcification (CAC) in European-derived populations [9-11]. Despite presence of more severe conventional CVD risk factors, AAs have markedly lower amounts of CAC, carotid artery CP, and aorta CP than EAs [12,13], along with significantly reduced rates of myocardial infarction when provided equal access to healthcare [14-16]. Relationships between conventional CVD risk factors and subclinical CVD do not appear to differ by race, suggesting that novel risk factors including cytokines and genetic variation may contribute to population-specific risks for CP and CVD [17].

As inflammation has emerged at the core pathophysiology of both diabetic nephropathy and atherosclerosis, we sought to investigate the relationships between serum MCP-1 concentrations with albuminuria, kidney function, and vascular calcification in a well-characterized cohort of AAs with type 2 diabetes (T2D) in the African American-Diabetes Heart Study (AA-DHS). Previous reports indicated that inflammation is a protracted process, occurring from the early stages of nephropathy (eGFR $>90 \mathrm{ml} / \mathrm{min} / 1.73 \mathrm{~m}^{2}$ and microalbuminuria) in patients with type 1 diabetes (T1D) $[18,19]$. Presence of inflammation in patients with chronic kidney disease (CKD) has been associated with carotid intimal-medial thickness [20] and increased risk of cardiovascular death [21]. Similarly, vascular endothelial damage begins before it becomes clinically apparent, at early stages of kidney disease (GFR $>90 \mathrm{ml} / \mathrm{min} / 1.73 \mathrm{~m}^{2}$ ) [22]. Elucidation of inflammatory markers with impact on early kidney disease and vascular dysfunction may guide innovative therapies to prevent or reverse nephropathy and/or vascular damage. We hypothesized that serum MCP-1 concentration, a surrogate of systemic and vascular inflammation, changes in T2D patients in relation to kidney function and vascular integrity. As such, the relationships between serum MCP-1 concentrations with early diabetic nephropathy and vascular calcified plaque were examined.

\section{Methods}

\section{Study population}

The AA-DHS is an observational study conducted on a cohort of self-reported and unrelated AAs with T2D lacking advanced nephropathy. Participants with advanced nephropathy or end-stage renal disease were excluded. Recruitment was conducted from internal medicine clinics and community advertising, as previously published [23]. Briefly, participant examinations were conducted in the Clinical Research Unit of Wake Forest Baptist Medical
Center and included interviews for medical history and health behaviors, anthropometric measures, resting blood pressure (BP), electrocardiography, fasting blood sampling (total cholesterol, low density lipoprotein [LDL] cholesterol, high density lipoprotein [HDL] cholesterol, triglycerides, hemoglobin $\mathrm{A}_{1 \mathrm{c}}\left[\mathrm{HbA}_{1 \mathrm{c}}\right]$, glucose and high sensitivity C-reactive protein [hsCRP]), spot urine collection for albumin:creatinine ratio (ACR), and computed tomography (CT).

History of CVD was provided by participant report and medical record review. Individuals with a history of myocardial infarction or stroke were included; however, CP scores in the coronary arteries were excluded in participants who underwent prior coronary artery bypass grafting and in the carotid arteries in participants who underwent carotid endarterectomy. We assessed eGFR using the simplified MDRD study and CKD-EPI equations [24,25]. Serum creatinine concentration was measured using a modified kinetic Jaffe method and corrected for inter-laboratory differences and calibrated to the Cleveland Clinic [26]. Medications known to influence atherosclerosis (lipid lowering medications) and urine ACR (angiotensin-converting enzyme inhibitors [ACEi] and angiotensin-receptor blockers [ARB]) were recorded. The study was approved by the Institutional Review Board at the Wake Forest School of Medicine and all participants provided written informed consent.

\section{Vascular imaging}

$\mathrm{CP}$ in the coronary arteries (CAC), carotid arteries (CarCP), and infrarenal aorta (AorCP) were determined using multidetector computed tomography (MDCT4) with cardiac gating and capable of 500-millisecond temporal resolution using the segmented reconstruction algorithm (LightSpeed Qxi; General Electric Medical Systems, Waukesha, WI, USA). Techniques for the coronary and carotid scans have been described in detail [11]. In brief, participants were placed in the supine position on the CT couch over a quality control calibration phantom (Image Analysis, Inc., Columbia, KY, USA) for scans of the heart and abdomen. The abdomen scan series was used to measure AorCP. Technical factors for this series were: $120 \mathrm{kV}, 250 \mathrm{~mA}, 0.8$-second gantry rotation helical mode $(7.5 \mathrm{~mm} / \mathrm{s}), 2.5-\mathrm{mm}$ slice thickness, and standard reconstruction kernel. The display field of view was $35 \mathrm{~cm}$, resulting in a pixel dimension of 0.68 by $0.68 \mathrm{~mm}$. CT scans of the three vascular territories were analyzed on a G.E. Advantage Windows Workstation with the SmartScores software package (General Electric Medical Systems) using a modified Agatston scoring method, which adjusts for slice thickness and uses the conventional threshold of 130 Hounsfield units. 


\section{MCP-1 assay}

Serum MCP-1 was measured using an enzyme-linked immunosorbent assay (ELISA) (Quantikine ${ }^{\circledR}$ Human CCL2/MCP-1 ELISA; R\&D Systems, Minneapolis) in freshly thawed serum samples which had been stored at $-80 \mathrm{C}$ since collection. Analyses were performed in batches using ELISA kits from a single lot to minimize variability due to manufacturing variation. Intra- and inter-assay coefficients of variation for $\mathrm{MCP}-1$ were $4.0 \% / 3.4 \%$ at $62.5 \mathrm{pg} / \mathrm{ml}$ and $1.8 \% / 2.1 \%$ at $500 \mathrm{pg} / \mathrm{ml}$.

\section{Statistical methods}

Generalized linear models (GLM) were fitted to test for associations between serum MCP-1 concentration and diabetes duration, $\mathrm{HbA}_{1 \mathrm{C}}$, body mass index (BMI), urine ACR, eGFR, CAC, CarCP and AorCP [27]. MCP-1 values greater than $486.7 \mathrm{pg} / \mathrm{ml}$, corresponding to the $95^{\text {th }}$ percentile in the distribution, were winsorized to 486.7 [28]. The Box-Cox method was applied to identify the appropriate transformation best approximating the distributional assumptions of conditional normality and homogeneity of variance of the residuals [29]. This method suggested taking the natural log of $(\mathrm{CAC}+1)$, $(\mathrm{CarCP}+1)$ and $(\mathrm{AorCP}+1),(\mathrm{ACR}+1), \mathrm{CRP}, \mathrm{MDRD}$ and CKD eGFR, the inverse of $\mathrm{HbA}_{1 \mathrm{c}}$ and the inverse square root of BMI to minimize the influence of extremely large covariate values on parameter estimates in the models. No transformation was required for eGFR. GLM models were fitted using the winsorized values of MCP-1 as the dependent variable. After an unadjusted analysis, adjustments for age, sex, smoking, $\mathrm{HbA}_{1 \mathrm{c}}, \mathrm{BMI}$, and LDL levels were incorporated. Urine ACR was analyzed both as categorical variable and as a continuous variable. The models used to test for association between BMI and $\mathrm{HbA}_{1 \mathrm{c}}$ with MCP-1 contained one less variable than the fully adjusted models between MCP-1 and other variables. Inter-active effects between BMI and MCP-1 on kidney function measures were also performed. Interaction effects were evaluated by testing for the direct interaction effect by including the centered product of BMI by MCP-1 and performing the association analysis between MCP-1 and the kidney function measures stratified by BMI where the sample was stratified into two subgroups (non-obese: BMI $<30.0 \mathrm{~kg} / \mathrm{m}^{2}$ and obese: BMI $\geq 30.0 \mathrm{~kg} / \mathrm{m}^{2}$ ). Type III sum of squares were also computed to evaluate the effect of eGFR adjusted for ACR (and vice-versa) and all other covariates on the vascular calcification and renal function measures.

\section{Results}

The study included 479 unrelated AAs with T2D (57\% women), $50.7 \%$ with hypertension (HTN), with mean \pm SD (median) age $55.6 \pm 9.5$ (55.0) years, diabetes duration $10.3 \pm 8.2(8.0)$ years, and BMI $35.5 \pm 8.7$ (34.0) $\mathrm{kg} / \mathrm{m}^{2}$ (Table 1). Participants were stratified by baseline urine ACR into non-albuminuric (urine ACR $<30 \mathrm{mg} / \mathrm{g}$; $\mathrm{n}=300$ ) and albuminuric (urine ACR $\geq 30 \mathrm{mg} / \mathrm{g} ; \mathrm{n}=179$ ). Characteristics of the cohort included serum MCP-1 levels $262.9 \pm 239.1(224.4) \mathrm{pg} / \mathrm{ml}$, hsCRP $1.1 \pm 1.8(0.5)$ $\mathrm{mg} / \mathrm{dl}, \mathrm{MDRD}$ eGFR $95.2 \pm 27.2(93.3) \mathrm{ml} / \mathrm{min} / 1.73 \mathrm{~m}^{2}$, CKD-EPI eGFR 92.4 $\pm 23.3(92.0) \mathrm{ml} / \mathrm{min} / 1.73 \mathrm{~m}^{2}$, and urine ACR $149.7 \pm 566.7$ (14.0) mg/g. There were no between gender differences in serum MCP-1 levels (267.8 \pm $242.0(229.3) \mathrm{pg} / \mathrm{ml}$ in women, and $256.5 \pm 235.4$ (212.8) $\mathrm{pg} / \mathrm{ml}$ in men, $\mathrm{P}=0.26)$. CAC was present in $62.7 \%$ of participants, $48.5 \%$ had detectable CarCP, and 77.9\% detectable AorCP. CKD-EPI and MDRD determined eGFRs were highly correlated (Spearman correlation $=0.93$ ).

Subjects with albuminuria had a longer diabetes duration by mean \pm SD $2.1 \pm 0.2$ years $(\mathrm{P}=0.0007)$, higher prevalence of $\mathrm{HTN}$ ( $62 \%$ vs. $44 \%, \mathrm{P}=0.0001)$, higher $\mathrm{BP}$ values with mean $\pm \mathrm{SD}$ difference of $8.9 \pm 5.4 \mathrm{mmHg}$ in systolic BP $(\mathrm{P}<0.0001)$ and $2.9 \pm 0.9 \mathrm{mmHg}$ in diastolic $\mathrm{BP}(\mathrm{P}=0.008)$, and were more often prescribed $\mathrm{ARB}$ and insulin (Table 1). Differences in biochemical parameters were also noted, with the albuminuric group having higher HbA1c, total cholesterol, triglycerides, and serum creatinine; and lower fasting glucose and HDL (Table 2). Modeled as a continuous variable, albuminuria was negatively associated with eGFR (parameter estimates and P-values of -0.0014 and 0.04 for CKD-EPI eGFR, and -0.0015 and 0.06 for MDRD eGFR).

In the univariate analysis, serum MCP-1 levels had negative association with Log (eGFR) and trended towards positive association with Log (urine ACR+1). Adjusted models including demographic characteristics (age, sex, smoking, BMI,) and laboratory values $\left(\mathrm{HbA}_{1 \mathrm{c}}\right.$, LDL) maintained significant evidence of negative association between MCP-1 and Log (eGFR) (parameter estimate $-0.0003, \mathrm{P}=0.001$ ) and detected significant positive association with urine ACR after logarithmic transformation (parameter estimate 0.0021, $\mathrm{P}=0.04$ ) (Table 3). Since urine ACR is associated with eGFR, we analyzed the relationship between MCP-1 and eGFR based on adjusting for $\log (\mathrm{ACR}+1)$, in a fully adjusted model. Compared to ACR alone (parameter estimate -0.0135, $\mathrm{P}=0.05), \mathrm{MCP}-1$ had the strongest association with CKD-EPI eGFR (parameter estimate $-0.0004, \mathrm{P}=0.002$ ) (Table 4).

We next assessed whether there is a correspondence between MCP-1, ACR, eGFR, and vascular CP. No association was detected between MCP-1 and CAC, CarCP, or AorCP in either unadjusted or adjusted models (Table 3). However, albuminuria was independently and significantly associated with vascular CP in all three vascular beds, while eGFR did not exhibit an association (Table 5). 
Table 1 Demographic characteristics of study participants by urine albumin: creatinine ratio

\begin{tabular}{|c|c|c|c|c|c|c|c|c|c|c|c|c|c|}
\hline \multirow[t]{2}{*}{ Variable } & \multicolumn{4}{|c|}{ Urine $A C R<30(N=300)$} & \multicolumn{4}{|c|}{ Urine $A C R \geq 30(N=179)$} & \multicolumn{4}{|c|}{ ALL (N=479) } & \multirow[t]{2}{*}{ P-value } \\
\hline & Mean & Median & SD & IQR & Mean & Median & SD & IQR & Mean & Median & SD & IQR & \\
\hline Age (years) & 55.9 & 56.0 & 9.6 & 13.0 & 55.0 & 53.0 & 9.5 & 13.0 & 55.6 & 55.0 & 9.5 & 13.0 & 0.32 \\
\hline Diabetes duration (years) & 9.5 & 7.0 & 8.2 & 8.0 & 11.6 & 10.0 & 8.0 & 8.0 & 10.3 & 8.0 & 8.2 & 8.0 & 0.0007 \\
\hline HTN n (\%) & 132 & & $(44.0)$ & & 111 & & (62.0) & & 243 & & $(50.7)$ & & 0.0001 \\
\hline BMI $\left(\mathrm{kg} / \mathrm{m}^{2}\right)$ & 35.5 & 34.1 & 8.5 & 10.0 & 35.6 & 33.6 & 9.2 & 11.3 & 35.5 & 34.0 & 8.7 & 10.6 & 0.83 \\
\hline Systolic BP (mm Hg) & 129.9 & 129.0 & 16.2 & 21.0 & 138.8 & 137.0 & 21.6 & 27.5 & 133.2 & 132.0 & 18.9 & 24.0 & $<.0001$ \\
\hline Diastolic BP (mm Hg) & 76.5 & 76.0 & 10.9 & 14.5 & 79.4 & 80.0 & 11.8 & 16.0 & 77.6 & 77.0 & 11.3 & 15.0 & 0.008 \\
\hline \multicolumn{14}{|l|}{ Smoking n (\%) } \\
\hline Past & 114 & & (38.0) & & 55 & & (30.7) & & 169 & & (35.3) & & 0.08 \\
\hline Current & 61 & & $(20.3)$ & & 51 & & $(28.5)$ & & 112 & & $(23.4)$ & & \\
\hline ACEi n (\%) & 116 & & $(38.7)$ & & 75 & & $(41.9)$ & & 191 & & (39.9) & & 0.48 \\
\hline$\overline{A R B} n(\%)$ & 37 & & $(12.3)$ & & 34 & & $(19.0)$ & & 71 & & $(14.8)$ & & 0.04 \\
\hline Lipid lowering med n (\%) & 148 & & $(51.0)$ & & 93 & & $(52.5)$ & & 241 & & (51.6) & & 0.75 \\
\hline Insulin n (\%) & 100 & & (33.3) & & 93 & & $(52.0)$ & & 193 & & $(40.3)$ & & $<0.0001$ \\
\hline TZD n (\%) & 37 & & $(12.3)$ & & 19 & & (10.6) & & 56 & & $(11.7)$ & & 0.57 \\
\hline
\end{tabular}

$A C R$, albumin: creatinine ratio; $S D$, standard deviation; $I Q R$, interquartile range; $B M I$, body mass index; $B P$, blood pressure; $A C E i$, angiotensin- converting enzyme inhibitor; $A R B$, angiotensin receptor blocker; $H T N$, hypertension; TZD, thiazolidinediones.

Relationships between serum MCP-1 with diabetes duration, BMI, and hsCRP were also assessed. No correlations were observed between serum MCP-1 and diabetes duration or hsCRP. Serum MCP-1 levels correlated with BMI, and this remained significant in the adjusted model $(\mathrm{P}=0.01)$ (Table 3$)$. To assess whether BMI impacts the relationship between MCP-1 and kidney function, association analyses were run with participants stratified as obese (BMI $\geq 30.0)$ and non-obese (BMI
$<30.0$ ). We found no evidence of an interaction effect between BMI and MCP-1 on either eGFR or urine ACR. As shown in Table 6, MCP-1 association parameters in obese participants were similar to those in the non-obese group $(-0.0004$ vs. $-0.0004, \mathrm{P}=0.75$, for the interaction effect on Log (eGFR); and 0.0017 vs. $0.0013, \mathrm{P}=0.68$, for the effect on $\log ($ urine $A C R+1)$ ). Evidence of an association between MCP-1 and kidney function remained significant in BMI stratified analyses, with

Table 2 Laboratory and imaging data by urine albumin: creatinine ratio

\begin{tabular}{|c|c|c|c|c|c|c|c|c|c|c|c|c|c|}
\hline \multirow[t]{2}{*}{ Variable } & \multicolumn{4}{|c|}{ Urine $A C R<30(N=296)$} & \multicolumn{4}{|c|}{ Urine $A C R \geq 30(N=175)$} & \multicolumn{4}{|c|}{ ALL $(\mathrm{N}=471)$} & \multirow[t]{2}{*}{ P-value } \\
\hline & Mean & Median & SD & IQR & Mean & Median & SD & IQR & Mean & Median & SD & IQR & \\
\hline Fasting Glucose (mg/dl) & 151.1 & 134 & 66.4 & 67 & 140.1 & 128 & 55.9 & 51 & 169.5 & 150 & 77.7 & 89 & $<.0001$ \\
\hline $\mathrm{HbA1c}(\%)$ & 7.8 & 7.4 & 1.7 & 2.2 & 8.7 & 8.4 & 2.2 & 2.7 & 8.1 & 7.7 & 2.0 & 2.4 & $<.0001$ \\
\hline Total Cholesterol (mg/dl) & 175.9 & 169.0 & 41.0 & 52.0 & 189.5 & 180.0 & 56.1 & 62.0 & 181.0 & 174.0 & 47.6 & 56.0 & 0.01 \\
\hline HDL-Cholesterol (mg/dl) & 49.2 & 47.0 & 13.8 & 16.5 & 45.3 & 43.0 & 13.1 & 16.0 & 47.8 & 46.0 & 13.6 & 17.0 & 0.0008 \\
\hline LDL-Cholesterol (mg/dl) & 104.3 & 98.0 & 34.3 & 44.0 & 112.8 & 106.0 & 44.9 & 58.0 & 107.4 & 101.0 & 38.7 & 48.0 & 0.08 \\
\hline Triglycerides (mg/dl) & 110.8 & 95.5 & 60.2 & 59.0 & 166.3 & 118.0 & 207.8 & 102.0 & 131.5 & 102.0 & 138.1 & 69.0 & 0.0001 \\
\hline Serum creatinine (mg/dl) & 0.9 & 0.9 & 0.3 & 0.3 & 1.0 & 1.0 & 0.3 & 0.4 & 1.0 & 0.9 & 0.3 & 0.3 & 0.01 \\
\hline Serum Calcium & 9.6 & 9.6 & 0.5 & 0.5 & 9.5 & 9.6 & 0.4 & 0.7 & 9.6 & 9.6 & 0.5 & 0.5 & 0.33 \\
\hline MDRD eGFR (ml/min) & 96.6 & 93.9 & 26.3 & 30.6 & 92.8 & 92.3 & 28.5 & 38.4 & 95.2 & 93.3 & 27.2 & 33.6 & 0.15 \\
\hline CKD-EPI eGFR (ml/min) & 93 & 92.0 & 21.9 & 32.4 & 91.3 & 92.6 & 25.5 & 44.6 & 92.4 & 92.0 & 23.3 & 35.8 & 0.53 \\
\hline Urine ACR (mg/g) & 8.2 & 5.3 & 7.3 & 8.8 & 386.9 & 96.0 & 878.6 & 185.0 & 149.7 & 14.0 & 566.7 & 55.8 & NA \\
\hline hsCRP (mg/dl) & 1 & 0.5 & 1.4 & 0.9 & 1.3 & 0.6 & 2.4 & 1.0 & 1.1 & 0.5 & 1.8 & 0.9 & 0.62 \\
\hline MCP-1 (pg/ml) & 250.7 & 214.7 & 199.5 & 119.0 & 283.3 & 234.1 & 293.2 & 135.1 & 262.9 & 224.4 & 239.1 & 127.4 & 0.15 \\
\hline CAC (mass score) & 222.7 & 4.5 & 518.0 & 170.0 & 377.8 & 32.3 & 784.7 & 351.8 & 280.1 & 13.5 & 633.8 & 235.5 & 0.001 \\
\hline CarCP (mass score) & 43.2 & 0.0 & 132.8 & 22.0 & 53.7 & 2.3 & 133.1 & 44.5 & 47.1 & 0.0 & 132.9 & 33.0 & 0.01 \\
\hline AorCP (mass score) & 1395 & 216.5 & 2426.0 & 1715.0 & 1990.0 & 380.0 & 3459.0 & 2301.0 & 1616.0 & 319.0 & 2864.0 & 1923.0 & 0.005 \\
\hline
\end{tabular}

$A C R$, albumin: creatinine ratio; $S D$, standard deviation; $I Q R$, interquartile range; $H b A 1 c$, hemoglobin $A 1 c ; H D L$, high density lipoprotein; $L D L$, low density lipoprotein; eGFR, estimated glomerular filtration rate; $h S C R P$, high sensitivity $C$-reactive protein; $M C P$-1, monocyte chemoattractant protein-1; $C A C$, coronary artery calcied plaque; $\operatorname{Car} C P$, carotid artery calcified plaque; Aor $C P$, infrarenal aorta calcified plaque. 
Table 3 MCP-1 associations in the unadjusted and fully adjusted models

\begin{tabular}{|c|c|c|c|c|c|c|}
\hline \multirow[t]{2}{*}{ Outcome } & \multicolumn{3}{|c|}{ Unadjusted } & \multicolumn{3}{|c|}{ Adjusted } \\
\hline & Estimate & StdErr & P-value & Estimate & StdErr & P-value \\
\hline Log(Diabetes duration) & 0.00060 & 0.00033 & 0.07 & 0.0003 & 0.0003 & 0.34 \\
\hline $1 /(\mathrm{HbA} 1 \mathrm{c})$ & $2.71 \mathrm{E}-06$ & $1.248 \mathrm{E}-05$ & 0.83 & $-7.70 \mathrm{E}-06$ & $1.23 \mathrm{E}-05$ & 0.53 \\
\hline $1 /$ sqrt(BMI) & $-1.37 \mathrm{E}-05$ & $8.53 \mathrm{E}-06$ & 0.11 & $-2.02 E-05$ & $8.28 \mathrm{E}-06$ & 0.01 \\
\hline Log(hsCRP) & 0.0003 & 0.0006 & 0.54 & -0.0001 & 0.0007 & 0.87 \\
\hline $\log (C A C+1)$ & 0.0006 & 0.001 & 0.57 & -0.0003 & 0.0015 & 0.82 \\
\hline $\log (\operatorname{CarCP}+1)$ & 0.0001 & 0.0008 & 0.86 & -0.0012 & 0.0011 & 0.31 \\
\hline $\log (A o r C P+1)$ & 0.0013 & 0.0012 & 0.25 & -0.001 & 0.0015 & 0.48 \\
\hline Log(Urine ACR+1) & 0.0013 & 0.0007 & 0.09 & 0.0021 & 0.001 & 0.04 \\
\hline Log(MDRD eGFR) & -0.0005 & 0.0001 & $<.0001$ & -0.0005 & 0.0001 & 0.006 \\
\hline Log(CKD-EPI eGFR) & -0.0004 & 0.0001 & $<.0001$ & -0.0003 & 0.0001 & 0.001 \\
\hline
\end{tabular}

$M C P-1$, monocyte chemoattractant protein-1; HbA1c, hemoglobin A1c; $B M I$, body mass index; $h s C R P$, high sensitivity $C$-reactive protein; $C A C$, coronary artery calcified plaque; $C a r C P$, carotid artery calcified plaque; $A o r C P$, infrarenal aorta calcified plaque; $A C R$, albumin: creatinine ratio; eGFR, estimated glomerular filtration rate.

Adjusted model includes age, sex, smoking, HbA1c, BMI, and LDL-cholesterol.

meta-analysis P-value $=0.001$ for Log (eGFR) and 0.04 for $\log$ (urine $A C R+1$ ).

\section{Discussion and conclusion}

This large cross-sectional study characterized relationships between serum MCP-1, albuminuria, eGFR and $\mathrm{CP}$ in the understudied AA population with T2D. After adjusting for covariates, higher serum MCP-1 levels associated positively with albuminuria and negatively with eGFR. In contrast, serum MCP-1 did not independently associate with atherosclerosis and subclinical CVD measured as $\mathrm{CP}$, suggesting differential molecular relationships between inflammation, risk for kidney disease, and CVD in AAs with T2D.

The pathophysiologic connection between atherosclerosis, CAC, albuminuria and kidney dysfunction is poorly understood at the molecular level. Previous studies demonstrated that MCP-1 is involved in the pathophysiology of atherosclerosis and DN in T1D and T2D [5,7]. MCP-1 is synthesized and secreted by a myriad of cells (monocytes, macrophages, endothelial cells, renal mesangial and tubular cells); and both tissue and systemic cells can contribute to detectable serum MCP-1 levels. In the hyperglycemic milieu, MCP-1 is produced by resident renal endothelial cells, mesangial cells,

Table 4 Association between MCP-1, eGFR, and ACR in the fully adjusted model

\begin{tabular}{lllll}
\hline Dependent & Parameter & Estimate & StdErr & P-value \\
\hline Log(MDRD eGFR) & MCP-1 & -0.0004 & 0.0001 & 0.002 \\
\hline Log(MDRD eGFR) & Log(ACR+1) & -0.0133 & 0.0078 & 0.08 \\
\hline Log(CKD-EPI eGFR) & MCP-1 & -0.0004 & 0.0001 & 0.002 \\
\hline Log(CKD-EPI eGFR) & Log(ACR+1) & -0.0135 & 0.0072 & 0.05 \\
\hline
\end{tabular}

$M C P-1$, monocyte chemoattractant protein-1; eGFR, estimated glomerular filtration rate; $A C R$, albumin: creatinine ratio.

Covariates included in the model are age, sex, smoking, HbA1c, BMI, and LDL. podocytes, and tubular epithelial cells; as well as by circulating or infiltrating monocytes/macrophages [30]. Several reports attest to the positive correlation between tissue MCP-1 expression and urine levels with albuminuria, mesangial proliferation, and interstitial fibrosis in a wide range of kidney diseases in humans [8,31-36]. In small studies comprised of European-derived participants with T1D or T2D, ELISA-based measurements of serum MCP-1 did not correlate with albuminuria $[30,34]$. It has been proposed that while the histopathology in diabetic kidney disease has remarkable similarity between type 1 and type 2 diabetes, and between population groups, the pathogenetic background may differ between AAs and EAs, and T2D or T1D [37]. Other longitudinal studies comprised of EAs with T1D, found that urine MCP-1 levels were significantly higher in patients with early nephropathy $(\mathrm{GFR}<90 \mathrm{ml} / \mathrm{min}$ and microalbuminuria) relative to those without nephropathy, with no difference in serum MCP-1 levels. $[18,19]$ Relative to EAs, it is possible that inflammatory pathways are upregulated in AAs. Previous studies have shown that AAs have higher serum CRP and interleukin-6 (IL-6) concentrations and display heightened oxidative stress and inflammation based on in vitro human umbilical vein endothelial cells (HUVECs) studies [38,39]. It is biologically plausible that MCP-1 may play differential roles in the pathophysiology of DN based on the type of diabetes and ethnic background.

We originally postulated that inflammation is a common mediator for both subclinical kidney disease and CVD in AAs with T2D and that systemic MCP-1 levels would correlate with markers of kidney disease and atherosclerosis. We found that a higher burden of vascular calcification was present in those with albuminuria, but $\mathrm{CP}$ did not associate with serum MCP-1 levels. Other 
Table 5 Type III mean squares and association between CP, ACR, and MCP-1

\begin{tabular}{|c|c|c|c|c|c|}
\hline Dependent & Model & Predictor & Estimate & StdErr & P-value \\
\hline \multirow[t]{9}{*}{ CAC } & ACR + all covariates in the adjusted model & $\log (A C R+1)$ & $1.5 \mathrm{E}-01$ & $6.6 \mathrm{E}-02$ & 0.02 \\
\hline & eGFR + all covariates in the adjusted model & eGFR & 1.7E-04 & 4.3E-03 & 0.96 \\
\hline & ACR and MCP-1 + all covariates in the adjusted model & $\log (A C R+1)$ & $1.5 \mathrm{E}-01$ & $6.6 \mathrm{E}-02$ & 0.02 \\
\hline & & MCP-1 & $-1.7 \mathrm{E}-04$ & $1.1 \mathrm{E}-03$ & 0.87 \\
\hline & eGFR and MCP-1+ all covariates in the adjusted model & eGFR & $2.0 \mathrm{E}-04$ & $4.4 \mathrm{E}-03$ & 0.96 \\
\hline & & $\mathrm{MCP}-1$ & $6.0 \mathrm{E}-05$ & $1.1 \mathrm{E}-03$ & 0.95 \\
\hline & ACR, eGFR and MCP-1+ all covariates in the adjusted model & eGFR & $6.9 \mathrm{E}-04$ & 4.4E-03 & 0.87 \\
\hline & & $\log (A C R+1)$ & $1.5 \mathrm{E}-01$ & $6.6 \mathrm{E}-02$ & 0.02 \\
\hline & & $\overline{\mathrm{MCP}-1}$ & $-1.4 \mathrm{E}-04$ & $1.1 \mathrm{E}-03$ & 0.89 \\
\hline \multirow[t]{9}{*}{ CarCP } & ACR + all covariates in the adjusted model & $\log (A C R+1)$ & $1.1 \mathrm{E}-01$ & $5.1 \mathrm{E}-02$ & 0.02 \\
\hline & eGFR + all covariates in the adjusted model & eGFR & $-4.3 \mathrm{E}-03$ & $3.4 \mathrm{E}-03$ & 0.20 \\
\hline & ACR and MCP-1 + all covariates in the adjusted model & $\log (A C R+1)$ & $1.1 \mathrm{E}-01$ & $5.2 \mathrm{E}-02$ & 0.02 \\
\hline & & $\mathrm{MCP}-1$ & $3.3 \mathrm{E}-05$ & $8.5 \mathrm{E}-04$ & 0.96 \\
\hline & eGFR and MCP-1+ all covariates in the adjusted model & eGFR & $-4.2 \mathrm{E}-03$ & $3.4 \mathrm{E}-03$ & 0.21 \\
\hline & & MCP-1 & $5.7 \mathrm{E}-05$ & $8.6 \mathrm{E}-04$ & 0.94 \\
\hline & ACR, eGFR and MCP-1+ all covariates in the adjusted model & eGFR & $-3.9 \mathrm{E}-03$ & $3.4 \mathrm{E}-03$ & 0.25 \\
\hline & & $\log (A C R+1)$ & $1.1 \mathrm{E}-01$ & $5.2 \mathrm{E}-02$ & 0.03 \\
\hline & & MCP-1 & $-1.1 \mathrm{E}-04$ & $8.6 \mathrm{E}-04$ & 0.90 \\
\hline \multirow[t]{9}{*}{ AorCP } & ACR + all covariates in the adjusted model & $\log (A C R+1)$ & $1.9 \mathrm{E}-01$ & $6.9 \mathrm{E}-02$ & 0.005 \\
\hline & eGFR + all covariates in the adjusted model & eGFR & $-5.2 \mathrm{E}-03$ & $4.4 \mathrm{E}-03$ & 0.24 \\
\hline & ACR and MCP-1 + all covariates in the adjusted model & $\log (A C R+1)$ & $1.9 \mathrm{E}-01$ & $6.9 \mathrm{E}-02$ & 0.006 \\
\hline & & $\overline{\mathrm{MCP}-1}$ & $6.4 \mathrm{E}-04$ & $1.1 \mathrm{E}-03$ & 0.56 \\
\hline & eGFR and MCP-1+ all covariates in the adjusted model & eGFR & $-4.8 \mathrm{E}-03$ & $4.5 \mathrm{E}-03$ & 0.28 \\
\hline & & $\overline{\mathrm{MCP}-1}$ & 7.7E-04 & $1.1 \mathrm{E}-03$ & 0.49 \\
\hline & ACR, eGFR and MCP-1+ all covariates in the adjusted model & eGFR & $-4.2 \mathrm{E}-03$ & $4.5 \mathrm{E}-03$ & 0.34 \\
\hline & & $\log (A C R+1)$ & $1.9 \mathrm{E}-01$ & $6.9 \mathrm{E}-02$ & 0.007 \\
\hline & & MCP-1 & $4.9 \mathrm{E}-04$ & 1.1E-03 & 0.66 \\
\hline
\end{tabular}

$C P$, calcified plaque; $A C R$, albumin: creatinine ratio; eGFR, estimated glomerular filtration rate; $M C P-1$, monocyte chemoattractant protein-1; $C A C$, coronary artery calcified plaque; $C a r C P$, carotid artery calcified plaque; $A o r C P$, infrarenal aorta calcified plaque.

The covariates included in the adjusted model are age, sex, smoking, HbA1c, BMI, and LDL.

studies demonstrated that serum MCP-1 levels correlate with CVD outcomes following acute coronary events, independent of traditional CVD risk factors [40]. Nevertheless, these studies did not examine the effect of serum MCP-1 on CV events based on kidney function or independent of the association with urine albumin excretion and eGFR. As in the present report, a large population-based sample from the Dallas Heart
Study did not observe an association between serum MCP-1 and CAC after adjusting for age and other covariates [41].

This is the first report of which we are aware detecting associations between serum MCP-1 with albuminuria and eGFR in AA patients with T2D and early nephropathy. Study participants were AAs without advanced kidney disease and no differences in serum MCP-1 levels

Table 6 Fully adjusted MCP-1 associations stratified by BMI

\begin{tabular}{|c|c|c|c|c|c|c|c|c|c|}
\hline & \multicolumn{5}{|c|}{ CKD-EPI eGFR } & \multicolumn{4}{|c|}{ Urine ACR } \\
\hline & $\mathbf{N}$ & Estimate & StdErr & P-meta & P-inter & Estimate & StdErr & P-meta & P-inter \\
\hline $\mathrm{BMI}<30.0$ & 134 & -0.0004 & 0.0002 & 0.001 & 0.75 & 0.0017 & 0.0015 & 0.04 & 0.68 \\
\hline $\mathrm{BMI} \geq 30.0$ & 345 & -0.0004 & 0.0001 & & & 0.0013 & 0.0009 & & \\
\hline
\end{tabular}

eGFR, estimated glomerular filtration rate; $A C R$, albumin: creatinine ratio; $B M I$, body mass index.

Results were adjusted for age, sex, smoking, HbA1c, and LDL-cholesterol.

eGFR and ACR values were logarithmically transformed.

P-meta is the P-value observed between MCP-1 and each outcome stratified by BMI.

$\mathrm{P}$-inter is the interaction P-value for the association difference between MCP-1 and each outcome in each BMI subgroup. 
were seen across genders. The nature of the factors determining elevated concentrations of serum MCP-1 in patients with T2D and early DN remains unknown. It is possible that high MCP-1 expression in the interstitial kidney macrophages leads to elevated systemic levels of MCP-1 proportional to the inflammatory and nephropathy stage. Another possibility, not mutually exclusive, is that serum MCP-1 levels are elevated in patients with early nephropathy due to dysregulated activation of systemic leukocytes. Indeed, several studies confirm an aberrant production of inflammatory cytokines and chemokines by circulating lymphocytes and monocytes in T2D patients with nephropathy [42]. Decreased filtration of extra-renally synthesized MCP-1 is less likely, since a minority of participants had an eGFR below $60 \mathrm{ml} / \mathrm{min} / 1.73 \mathrm{~m}^{2}$.

In addition to roles of MCP-1 in atherosclerosis and kidney disease, several studies implicated MCP-1 in the pathophysiology of obesity and insulin resistance $[43,44]$. In our sample of AAs with $\mathrm{T} 2 \mathrm{D}$, significant correlations were observed between MCP-1 and BMI, but not with diabetes duration or $\mathrm{HbA}_{1 \mathrm{c}}$. The association between adipose tissue and $\mathrm{MCP}-1$ raised the question whether the link between serum MCP-1 and renal function parameters could have been driven by the high prevalence of obesity in this cohort. Adjustment for BMI and cholesterol failed to modify the association and BMI-stratified effect sizes were not statistically different between obese and non-obese strata. As such, relationships between serum MCP-1 and kidney function were not impacted by obesity.

Significant relationships between MCP-1 with eGFR and albuminuria, coupled with lack of association with $\mathrm{CP}$, imply that MCP-1 does not mediate joint pathways implicated in co-existing kidney and CVD. However, the lack of a cross-sectional association between MCP-1 and burden of CP in AAs does not exclude a role for this molecule in the inflammatory component of atherosclerosis. Previous studies have shown that serum MCP-1 levels are higher in patients with active angina (compared to those with stable coronary disease), and higher levels predicted future coronary events and mortality following an acute coronary event $[45,46]$. In addition, serum MCP-1 levels have been associated with immunohistochemical indices of inflammation and matrix remodeling in the coronary atherosclerotic plaques of non-human primates [47]. The role of MCP-1 in CP should also be explored in EAs, a population with higher burden of vascular calcification than AAs $[12,13]$.

This study has important strengths and some limitations. AAs are known to display different patterns of nephropathy and CVD morbidity relative to EAs. The large and well phenotyped AA sample enabled simultaneous evaluation of a molecular biomarker potentially impacting albuminuria, eGFR, and subclinical atherosclerosis. Preserved kidney function in AA-DHS participants lessens concern that altered serum MCP-1 levels were due to kidney failure, whether mediated by poor renal excretion or inflammation-driven overproduction. Limitations include the cross-sectional nature of study measurements, rendering inability to secure a causal relationship between MCP-1 and early DN. Longitudinal studies characterizing relationships between MCP-1 and albuminuria and eGFR are warranted and could provide support for pharmacological MCP-1 inhibition during the incipient stages of DN [48]. Recent studies in mouse models suggest such treatment has promise [49].

In conclusion, MCP-1 serum concentrations manifest positive association with albuminuria and negative association with eGFR in AAs with T2D; without association with subclinical atherosclerosis. Relationships between MCP-1, albuminuria, eGFR, and vascular CP need to be evaluated in EAs and non-diabetic AAs. MCP-1 inhibition could provide a novel therapeutic strategy to prevent diabetic kidney disease in AAs with T2D.

\begin{abstract}
Abbreviations
$\mathrm{HbA}_{1 \mathrm{c}}$ : Hemoglobin A1c; AA(s): African American(s); AA-DHS: African American-Diabetes Heart Study; ACEi: Angiotensin-converting enzyme inhibitor; ACR: Urine albumin: creatinine ratio; AorCP: Infrarenal aorta calcified plaque; ARB: Angiotensin receptor blocker; BMI: Body mass index; BP: Blood pressure; CAC: Coronary artery calcified plaque; CarCP: Carotid artery calcified plaque; CCL2: Chemokine (C-C motif) ligand 2; CKD: Chronic kidney disease; CKD-EPI: Chronic Kidney Disease Epidemiology; CP: Calcified plaque; CT: Computed tomography; CVD: Cardiovascular disease; DN: Diabetic nephropathy; EA(s): European American(s); eGFR: Estimated glomerular filtration rate; HDL: High density lipoprotein; hsCRP: High sensitivity Creactive protein; HTN: Hypertension; LDL: Low density lipoprotein; MCP-

1: Monocyte chemoattractant protein-1; MDRD: Modification of Diet in Renal Disease Study; T1D: Type 1 diabetes; T2D: Type 2 diabetes;

TZD: Thiazolidinediones.
\end{abstract}

\section{Competing interests}

The authors report no conflicts of interest.

\section{Authors' contributions}

MM - study design, manuscript preparation; TCR - study design, MCP-1 assays, manuscript preparation; JD - statistical analysis, manuscript editing; DWB - manuscript editing; JJC - radiologic imaging and interpretation, manuscript editing; $\mathrm{CRH}$ - radiologic imaging interpretation; JX - database management; CSS - participant recruitment, manuscript editing; CDL statistical analysis, manuscript editing; $\mathrm{KAH}$ - study design, manuscript editing; BIF - study design, participant recruitment, supervision of data analyses, manuscript preparation. All authors read and approved the final manuscript.

\section{Acknowledgements}

This study was supported in part by the General Clinical Research Center of the Wake Forest University School of Medicine grant M01 RR07122; and NIDDK grant R01 DK071891 (BIF). The investigators acknowledge the cooperation of our participants and study recruiter Cassandra Bethea. The authors report no conflicts of interest.

\section{Author details}

${ }^{1}$ Department of Internal Medicine/Nephrology, Wake Forest School of Medicine, Medical Center Boulevard, Winston-Salem, NC 27157-1053, USA. ${ }^{2}$ Department of Pathology, Wake Forest School of Medicine, Winston-Salem, North Carolina 27157, USA. ${ }^{3}$ Division of Public Health Sciences, Wake Forest School of Medicine, Winston-Salem, North Carolina 27157, USA. ${ }^{4}$ Department 
of Internal Medicine/Endocrinology/Centers for Diabetes Research and Human Genomics, Wake Forest School of Medicine, Winston-Salem, North Carolina 27157, USA. ${ }^{5}$ Department of Radiology, Wake Forest School of Medicine, Winston-Salem, North Carolina 27157, USA. 'Division of Pediatric Nephrology, Washington University School of Medicine, St. Louis, MO 63110, USA

Received: 24 May 2012 Accepted: 18 October 2012

Published: 14 November 2012

\section{References}

1. Navarro-Gonzalez JF, Mora-Fernandez C, de Muros FM, Garcia-Perez J: Inflammatory molecules and pathways in the pathogenesis of diabetic nephropathy. Nat Rev Nephrol 2011, 7:327-340.

2. Galkina E, Ley K: Immune and inflammatory mechanisms of atherosclerosis (*). Annu Rev Immunol 2009, 27:165-197.

3. McNeill E, Channon KM, Greaves DR: Inflammatory cell recruitment in cardiovascular disease: murine models and potential clinical applications. Clin Sci (Lond) 2010, 118:641-655.

4. Nguyen D, Ping F, Mu W, Hill P, Atkins RC, Chadban SJ: Macrophage accumulation in human progressive diabetic nephropathy. Nephrology (Carlton) 2006, 11:226-231.

5. Gosling J, Slaymaker S, Gu L, Tseng S, Zlot CH, Young SG, et al: MCP-1 deficiency reduces susceptibility to atherosclerosis in mice that overexpress human apolipoprotein B. J Clin Invest 1999, 103:773-778.

6. Young BA, Johnson RJ, Alpers CE, Eng E, Gordon K, Floege J, et al: Cellular events in the evolution of experimental diabetic nephropathy. Kidney Int 1995, 47:935-944.

7. Chow FY, Nikolic-Paterson DJ, Ozols E, Atkins RC, Rollin BJ, Tesch GH: Monocyte chemoattractant protein-1 promotes the development of diabetic renal injury in streptozotocin-treated mice. Kidney Int 2006, 69:73-80.

8. Tesch GH: MCP-1/CCL2: a new diagnostic marker and therapeutic target for progressive renal injury in diabetic nephropathy. Am J Physiol Renal Physiol 2008, 294:F697-F701.

9. Gerstein HC, Mann JF, Yi Q, Zinman B, Dinneen SF, Hoogwerf B, et al: Albuminuria and risk of cardiovascular events, death, and heart failure in diabetic and nondiabetic individuals. JAMA 2001, 286(4):421-426.

10. Arnlov J, Evans JC, Meigs JB, Wang TJ, Fox CS, Levy D, et al: Low-grade albuminuria and incidence of cardiovascular disease events in nonhypertensive and nondiabetic individuals: the Framingham Heart Study. Circulation 2005, 112(7):969-975.

11. Freedman BI, Langefeld CD, Lohman KK, Bowden DW, Carr JJ, Rich SS, et al: Relationship between Albuminuria and Cardiovascular Disease in Type 2 Diabetes. J Am Soc Nephrol 2005, 16:2156-2161.

12. Bild DE, Detrano R, Peterson D, Guerci A, Liu K, Shahar E, et al: Ethnic differences in coronary calcification: the Multi-Ethnic Study of Atherosclerosis (MESA). Circulation 2005, 111(10):1313-1320.

13. Freedman $\mathrm{Bl}, \mathrm{Hsu} \mathrm{FC}$, Langefeld CD, Rich SS, Herrington DM, Carr JJ, et al: The impact of ethnicity and sex on subclinical cardiovascular disease: the Diabetes Heart Study. Diabetologia 2005, 48(12):2511-2518.

14. Hozawa A, Folsom AR, Sharrett AR, Chambless LE: Absolute and attributable risks of cardiovascular disease incidence in relation to optimal and borderline risk factors: comparison of African American with white subjects-Atherosclerosis Risk in Communities Study. Arch Intern Med 2007, 167:573-579.

15. Young BA, Rudser K, Kestenbaum B, Seliger SL, Andress D, Boyko EJ: Racial and ethnic differences in incident myocardial infarction in end-stage renal disease patients: the USRDS. Kidney Int 2006, 69:1691-1698.

16. Karter AJ, Ferrara A, Liu JY, Moffet HH, Ackerson LM, Selby JV: Ethnic disparities in diabetic complications in an insured population. JAMA 2002, 287:2519-2527.

17. Wagenknecht LE, Divers J, Bertoni AG, Langefeld CD, Carr JJ, Bowden DW, et al: Correlates of coronary artery calcified plaque in blacks and whites with type 2 diabetes. Ann Epidemiol 2011, 21:34-41.

18. Niewczas MA, Ficociello LH, Johnson AC, Walker W, Rosolowsky ET, Roshan $B$, et al: Serum concentrations of markers of TNFalpha and Fas-mediated pathways and renal function in nonproteinuric patients with type 1 diabetes. Clin J Am Soc Nephrol 2009, 4:62-70.
19. Wolkow PP, Niewczas MA, Perkins B, Ficociello LH, Lipinski B, Warram JH, et al: Association of urinary inflammatory markers and renal decline in microalbuminuric type 1 diabetics. J Am Soc Nephrol 2008, 19:789-797.

20. Stenvinkel P, Heimburger O, Paultre F, Diczfalusy U, Wang T, Berglund L, et al: Strong association between malnutrition, inflammation, and atherosclerosis in chronic renal failure. Kidney Int 1999, 55:1899-1911.

21. Stenvinkel $P$, Lindholm B, Heimburger M, Heimburger O: Elevated serum levels of soluble adhesion molecules predict death in pre-dialysis patients: association with malnutrition, inflammation, and cardiovascular disease. Nephrol Dial Transplant 2000, 15:1624-1630.

22. Mourad JJ, Pannier B, Blacher J, Rudnichi A, Benetos A, London GM, et al: Creatinine clearance, pulse wave velocity, carotid compliance and essential hypertension. Kidney Int 2001, 59:1834-1841.

23. Wagenknecht LE, Bowden DW, Carr JJ, Langefeld CD, Freedman BI, Rich SS: Familial aggregation of coronary artery calcium in families with type 2 diabetes. Diabetes 2001, 50:861-866.

24. Levey AS, Bosch JP, Lewis JB, Greene T, Rogers N, Roth D: A more accurate method to estimate glomerular filtration rate from serum creatinine: $a$ new prediction equation. modification of diet in renal disease study group. Ann Intern Med 1999, 130(6):461-470.

25. Levey AS, Stevens LA, Schmid CH, Zhang Y, Castro AF III, Feldman HI, et al: A new equation to estimate glomerular filtration rate. Ann Intern Med 2009, 150:604-612

26. Coresh J, Astor BC, McQuillan G, Kusek J, Greene T, Van LF, et al: Calibration and random variation of the serum creatinine assay as critical elements of using equations to estimate glomerular filtration rate. Am J Kidney Dis 2002, 39:920-929.

27. McCullagh P, Nelder J: Generalized Linear Models. Secondth edition. Boca Raton, Florida: Chapman and Hall/CRC Publishers; 1989

28. Hastings C, Mosteller F, Tukey JW, Winsor CP: Low moments for small samples: a comparative study of order statistics. Ann Math Stat 1947, 18:413-426.

29. Box GEP, Cox DR: An analysis of tranformations. J R StatSoc, Series B 1964, 26:211-246.

30. Banba N, Nakamura T, Matsumura M, Kuroda H, Hattori Y, Kasai K: Possible relationship of monocyte chemoattractant protein-1 with diabetic nephropathy. Kidney Int 2000, 58:684-690.

31. Rovin BH, Doe N, Tan LC: Monocyte chemoattractant protein-1 levels in patients with glomerular disease. Am J Kidney Dis 1996, 27:640-646.

32. Wada T, Yokoyama H, Su SB, Mukaida N, Iwano M, Dohi K, et al: Monitoring urinary levels of monocyte chemotactic and activating factor reflects disease activity of lupus nephritis. Kidney Int 1996, 49:761-767.

33. Yokoyama H, Wada T, Furuichi K, Segawa C, Shimizu M, Kobayashi K, et al: Urinary levels of chemokines (MCAF/MCP-1, IL-8) reflect distinct disease activities and phases of human IgA nephropathy. J Leukoc Biol 1998, 63:493-499.

34. Wada T, Furuichi K, Sakai N, Iwata Y, Yoshimoto K, Shimizu M, et al: Up regulation of monocyte chemoattractant protein-1 in tubulointerstitial lesions of human diabetic nephropathy. Kidney Int 2000, 58:1492-1499.

35. Morii T, Fujita H, Narita T, Shimotomai T, Fujishima H, Yoshioka N, et al: Association of monocyte chemoattractant protein-1 with renal tubular damage in diabetic nephropathy. J Diabetes Complications 2003, 17(1):11-15.

36. Munshi $R$, Johnson A, Siew ED, Ikizler TA, Ware LB, Wurfel MM, et al: MCP-1 Gene Activation Marks Acute Kidney Injury. J Am Soc Nephrol 2011, 22:165-175.

37. Ruggenenti $P$, Remuzzi G: Nephropathy of type 1 and type 2 diabetes: diverse pathophysiology, same treatment? Nephrol Dial Transplant 2000, 15:1900-1902

38. Paalani $M$, Lee JW, Haddad E, Tonstad S: Determinants of inflammatory markers in a bi-ethnic population. Ethn Dis 2011, 21:142-149.

39. Feairheller DL, Park JY, Sturgeon KM, Williamson ST, Diaz KM, Veerabhadrappa $\mathrm{P}$, et al: Racial differences in oxidative stress and inflammation: in vitro and in vivo. Clin Trans/ Sci 2011, 4:32-37.

40. Gonzalez-Quesada C, Frangogiannis NG: Monocyte chemoattractant protein-1/CCL2 as a biomarker in acute coronary syndromes. Curr Atheroscler Rep 2009, 11:131-138.

41. Deo R, Khera A, McGuire DK, Murphy SA, Meo Neto JP, Morrow DA, et al: Association among plasma levels of monocyte chemoattractant protein1 , traditional cardiovascular risk factors, and subclinical atherosclerosis. J Am Coll Cardiol 2004, 44:1812-1818. 
42. Wong CK, Ho AW, Tong PC, Yeung CY, Kong AP, Lun SW, et al: Aberrant activation profile of cytokines and mitogen-activated protein kinases in type 2 diabetic patients with nephropathy. Clin Exp Immunol 2007, 149:123-131.

43. Sartipy P, Loskutoff DJ: Monocyte chemoattractant protein 1 in obesity and insulin resistance. Proc Natl Acad Sci USA 2003, 100:7265-7270.

44. Sell $H$, Eckel J: Monocyte chemotactic protein-1 and its role in insulin resistance. Curr Opin Lipidol 2007, 18:258-262.

45. Matsumori A, Furukawa Y, Hashimoto T, Yoshida A, Ono K, Shioi T, et al: Plasma levels of the monocyte chemotactic and activating factor/ monocyte chemoattractant protein-1 are elevated in patients with acute myocardial infarction. J Mol Cell Cardiol 1997, 29:419-423.

46. de Lemos JA, Morrow DA, Sabatine MS, Murphy SA, Gibson CM, Antman $E M$, et al: Association between plasma levels of monocyte chemoattractant protein-1 and long-term clinical outcomes in patients with acute coronary syndromes. Circulation 2003, 107:690-695.

47. Register TC, Cann JA, Kaplan JR, Williams JK, Adams MR, Morgan TM, et al: Effects of soy isoflavones and conjugated equine estrogens on inflammatory markers in atherosclerotic, ovariectomized monkeys. J Clin Endocrinol Metab 2005, 90:1734-1740.

48. Xia M, Sui Z: Recent developments in CCR2 antagonists. Expert Opin Ther Pat 2009, 19:295-303.

49. Kang YS, Lee MH, Song HK, Ko GJ, Kwon OS, Lim TK, et al: CCR2 antagonism improves insulin resistance, lipid metabolism, and diabetic nephropathy in type 2 diabetic mice. Kidney Int 2010, 78:883-894.

doi:10.1186/1471-2369-13-148

Cite this article as: Murea et al:: Relationships between serum MCP-1 and subclinical kidney disease: African American-Diabetes Heart Study. BMC Nephrology 2012 13:148.

\section{Submit your next manuscript to BioMed Central and take full advantage of:}

- Convenient online submission

- Thorough peer review

- No space constraints or color figure charges

- Immediate publication on acceptance

- Inclusion in PubMed, CAS, Scopus and Google Scholar

- Research which is freely available for redistribution 